\title{
From implant novice to global leader in two decades
}

Interview by Caroline Holland

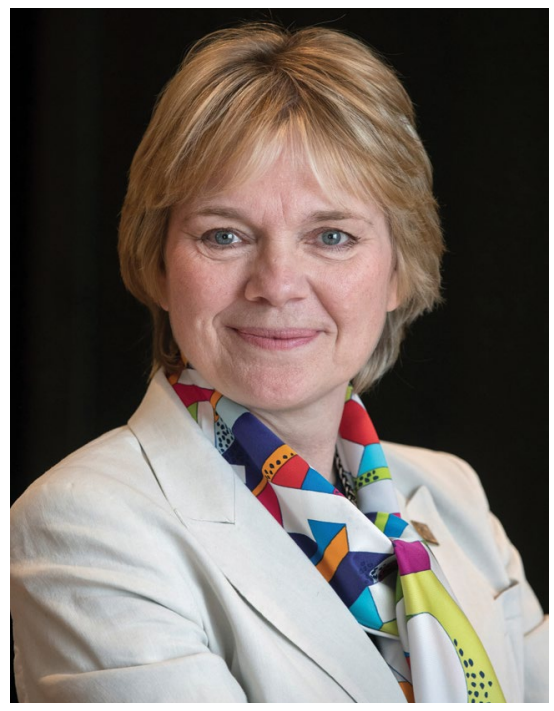

Dr Charlotte Stilwell

A plethora of 'firsts' can be claimed by Dr Charlotte Stilwell, the new President of the International Team for Implantology (ITI), the world's largest organisation dedicated to implant dentistry. Presiding over a membership of 18,000 clinicians across more than 100 countries, she is the first ITI President who is UK-based, female, Danish-born and from a prosthodontic background in general practice.

Dr Stilwell does not vaunt the achievements, however, pointing instead to the role of ITI in providing her with an academic home as well as invaluable peer support on her implant therapy journey.
'This is what the ITI does; it provides the ongoing, educational support and mentoring so that members develop competency and skills, as well as creating opportunities for involvement as you progress.'

A prosthodontist, she developed an interest in dental implants after moving from a general practice in South London to a specialist practice in Harley Street. One of her new colleagues was an ITI fellow and he encouraged her interest and mentored her. She joined the UK and Ireland section of ITI in 2005 as an educational speaker focusing on her area of expertise, removable implant overdenture solutions, was nominated as a fellow in 2007 and by 2010 had become a member of the international education committee,

'I was very fortunate that I was in an open-minded and forward thinking section that welcomed involvement. I think this encouragement is why so many us from overseas flourish in the UK.'

One of her greatest contributions has been a role in the development of a Foundation in Implant Dentistry (FID) course on behalf of the UK and Ireland section. This led to her having more roles at global level, including an appointment as the first Editor-in-Chief of the ITI online academy.

During her presidency, Dr Stilwell would like to see more women dentists become involved in implant dentistry which is a decidedly male-dominated discipline, more opportunities for dental team members within ITI and more engagement with dental schools and universities, through an offer of free, virtual campuses for hosting

ITI educational resources.

'Implant therapy is not yet widely taught at university at undergraduate level and I would like to change that. Not everyone wants to provide implants,' she says, 'but dental teams need to know how to care for implants and recognise when there are issues. Increasing numbers of patients of tomorrow will have an implant and as a profession we need to feel as comfortable around implants as we do around teeth.'

Another of Dr Stilwell's aims is to prioritise the needs and concerns of patients in implant therapy. For instance, rather than simply teaching sinus floor replacement as a technique, it needs to be taught within a patient-centred context and considered objectively against other applicable options.

This vision is being translated into an innovative session at the ITI online World Symposium in September when seven videos of patients discussing their implant needs will be presented and discussed, and delegates invited to pose questions to solutions and treatments.

'Belonging to the ITI is a phenomenal motivator. I am part of a community and a well-resourced organisation with a clear philosophy. It's saying something that I am as interested in my career now as I ever was and looking forward to the next four years.'

\section{CQC report on dental access during the pandemic}

The Care Quality Commission (CQC) has published the results of its analysis of primary dental care delivery during the COVID-19 pandemic. $^{1}$

The CQC analysed information from different sources, including feedback to its Give Feedback on Care service and to Healthwatch, data from the NHS Business Services Authority around NHS dental activity, and input from 102 providers of dental care between January and March 2021.

The key findings of the report were:

- Access to NHS dental care for all has been highlighted as an issue since long before the pandemic
- At the start of the pandemic, routine NHS dental services paused, and then practices introduced enhanced infection prevention and control measures to help prevent the spread of COVID-19

- The pandemic has compounded previous issues about access to dental services, as it has resulted in reduced capacity

- There has been an increase in feedback from the public expressing difficulties in accessing dental care during the pandemic, which can have a strong impact on people's general health and wellbeing
- CQC saw examples of dental providers adapting their practices well to respond to the pandemic

- Although there were some examples of dental services working well with other health and care providers in a community, there were also difficulties that prevented people from receiving a prompt, joined-up experience of care.

\section{Reference}

1. Care Quality Commission. COVID-19 Insight 10: Dental access during the pandemic. 19 May 2021. Available at: https://www.cqc.org.uk/publications/major-reports/ covid-19-insight-10-dental-access-during-pandemic (accessed 28 May 2021). 